\title{
The Scheme Research on Aqueduct with Three -way Prestressed Steel Strand Tension in South-to-North Water Diversion Project
}

\author{
Wen Chen \\ College of hydraulic \& environmental engineering \\ China Three Gorges University \\ Yichang, Hubei, 443002, P.R. China \\ wenchen910419@foxmail.com
}

\author{
Li Xuehao \\ China Gezhouba Group NO.1 Engineering Co., Ltd \\ China Energy Engineering Group Co., Ltd \\ Yichang, Hubei, 443002, P.R. China
}

\author{
Peng Hui*, Jin Ke, Wu Fan, Yin Shaofei \\ College of hydraulic \& environmental engineering \\ China Three Gorges University \\ Yichang, Hubei, 443002, P.R. China \\ hpeng1976@163.com
}

\begin{abstract}
The large aqueduct has the characteristics of large streamflow, heavy load and complicated structure and so on. Different from the high dams, most of the aqueducts are constructed with the thin-walled concrete structures. When analyzing the structure of the aqueduct, people often only consider that after the completion of the overall project, whether the aqueduct meets the design requirements or not, ignoring the large thin-wall aqueduct deformation and stress distribution under different working conditions during the construction period, and other construction technical issues that may emerge. It is not so clear whether the prestressed tension load classification and tensioning sequence changes may significantly affect the aqueduct structure system. Therefore, further study is needed. Under the premise of ensuring the safety of the aqueduct structure and the convenient construction, this paper puts forward a feasible plan of three hierarchical tensioning of prestressed steel strand and the suitable release time of the aqueduct body weight, providing the theoretical and technical support for the similar large three-way prestressed aqueduct and hydraulic structure construction.
\end{abstract}

Keywords: aqueduct; prestressed steel strand; tension by stages; thin-walled concrete structure; construction

\section{INTRODUCTION}

Located in Shenxing town, Mancheng county, Baoding city, Hebei province, the Caohe aqueduct, which is about $30 \mathrm{~km}$ away from Baoding and $9 \mathrm{~km}$ northwest of Mancheng county, is a larger span cross structures on the mid- route of South - to North Water Transfer Project. The Caohe aqueduct consists of import period, trough body(Including the landing rectangle slot, 20 meters across three slots for more than a league of side wall section and more than a league of 30 meters across three slot

This research was supported by NSFC (National Natural Science Foundation of China) (Granted No.: 51379108) side wall sections and the import and export connections) and export period[1-3]. The building in this project is level I. The primary building is level I building, the intensity of resisting an earthquake is 6 on the Richter scale.

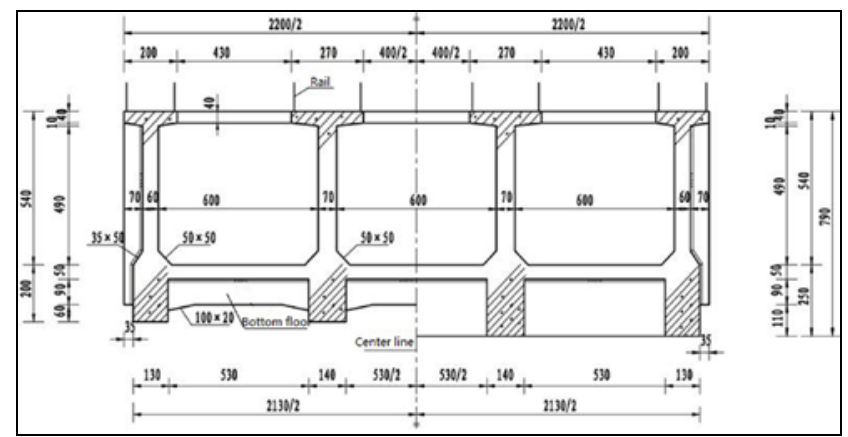

Fig. 1 The Caohe aqueduct`s cross-sectional dimensions

Trough body using three-way prestressed structure, prestressed steel strand in main trough body using both straight and curved shape, the diameter of the prestress wire is $15.2 \mathrm{~mm}$ [4]. Prestressed reinforcement arrangement is as follows:

\section{(1) Longitudinal prestressed steel strand}

To each side beam configuration layout total 9 hole, $83 \Phi$ j15.2 steel strands, 33 is curve, and another 50 is straight line, adopt tensioning on both ends. Hole prestressed tendon respectively: A1 type channel for $8 \Phi \mathrm{j} 15.2 \mathrm{x} 5$, B1 type channel for $11 \Phi \mathrm{j} 15.2 \times 3$ and G1 type channel for $10 \Phi \mathrm{j} 15.2 \mathrm{x}$ 1.18 hole on both sides of the side beam, beam of 166 strands.

To each longitudinal beam, each longitudinal beam configuration with 13 channel, $128 \Phi$ j15.2 steel strands, including 44 is curve, another 84 is straight line, adopt tensioning on both ends. Channel of prestressing tendon is 
respectively: $\mathrm{C} 1$ hole is $10 \Phi \mathrm{j} 15.2 \times 5$, D1 type channel for $9 \Phi$ j15.2 x 2, E channel for $11 \Phi \mathrm{j} 15.2 \times 4$, type H1 channel for 8 $\Phi$ j15.2 x 2.Two floor, decorate a 24 hole, configuration 96 beam $\Phi$ j15.2 steel strand, each groove 32 beam, channel prestressed tendon is: $4 \Phi \mathrm{j} 15.2 \times 24$.

(2)Transverse prestressed steel strand

Transverse prestressed reinforcement is configured by the unit of cross rib, cross section in each unit layout 3 channel, for $14 \Phi \mathrm{j} 15.2 \times 1$ (L1), $5 \Phi \mathrm{j} 15.2 \times 2$ (K1). The 10 hole layout for curve, both ends tension;20 channel for linear layout, single tension. Bearing cross section per unit 3 channel, $17 \Phi \mathrm{j} 15.2 \mathrm{x}$ 1 (J1), $3 \Phi$ j15.2 × 2 (I1).J1 type channel for curve layout, both ends of the tension;I1 channel is linear layout, unidirectional tension

\section{(3) Vertical prestressed steel strand}

Vertical prestressed reinforcement is linear arrangement, still configured by the unit of cross rib and symmetrical configuration, a total of 36 hole, $252 \Phi$ j15.2 steel strands ,each unit have 3 channel configurations, the inside bore 2 (M1), lateral $1(\mathrm{~N})$, is $7 \Phi \mathrm{j} 15.2 \times 3$, top tensioned.

\section{INTRODUCTION TO THE THREE-WAY PRESTRESSED CLASSIFICATION TENSIONING CALCULATION MODEL}

Due to the Caohe's characteristics of large streamflow, large span and large cross section, etc and the first phase of the south-to-north water transfer project, and the overall space structure of aqueduct, which needs an overall analysis, the paper adopts the ANSYS software to simulate calculation.

\section{A. Coordinate direction rules}

(1) The X direction: the aqueduct transverse direction, to the right for positive

(2) The Y direction: the aqueduct vertical, to the upward for positive

(3) The $\mathrm{Z}$ direction: the aqueduct at the direction of flow, $\mathrm{Z}$ direction Cross out for positive

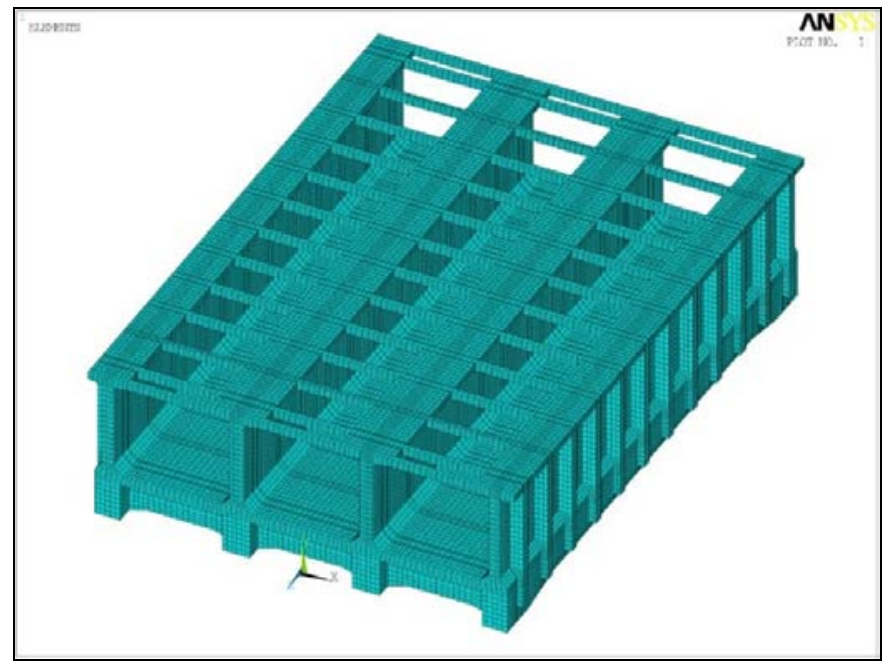

Fig. 2 Finite element analysis model of aqueduct

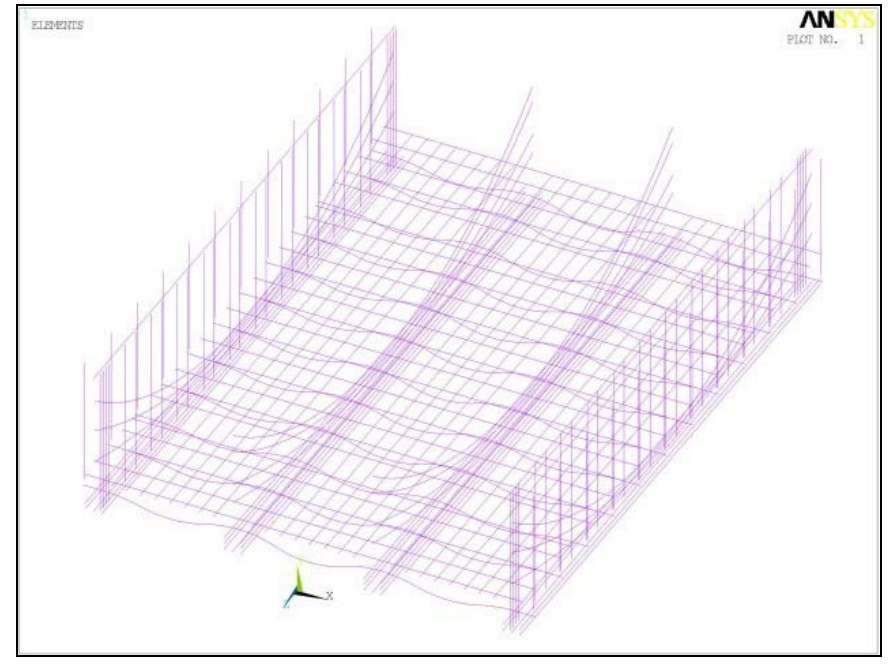

Fig.3 Model for calculating the aqueduct three-way prestressed steel strand

\section{B. Calculated parameters}

(1) Concrete. Strength grade C50, according to the hydraulic concrete structure design code (DL/T5057-1996) [56], structural calculation design parameters: elastic modulus $\mathrm{EC}=3.45 \times 104 \mathrm{~N} / \mathrm{mm}$; Poisson's ratio=0.167; Density $\rho=$ $2515 \mathrm{~kg} / \mathrm{m} 3$.

(2) The steel strand: elastic modulus EC $=1.95 \times 105$ $\mathrm{N} / \mathrm{mm}$; Poisson's ratio u $=0.30$; Linear expansion coefficient 2 E-005; Density $\rho=7850 \mathrm{~kg} / \mathrm{m} 3$.

The selected material parameters are shown in Table 1.

TABLE 1 ATERIAL PARAMETERS

\begin{tabular}{|l|c|c|c|c|c|}
\hline \multicolumn{1}{|c|}{ Parts } & material & $\begin{array}{c}\text { density } \\
\left(\mathbf{K g} / \mathbf{m}^{\mathbf{3}}\right)\end{array}$ & $\begin{array}{c}\text { elastic } \\
\text { modulus } \\
\mathbf{( G P a )}\end{array}$ & $\begin{array}{c}\text { Poisson's } \\
\text { ratio }\end{array}$ & CTE \\
\hline $\begin{array}{l}\text { The } \\
\text { entity } \\
\text { part }\end{array}$ & $\begin{array}{c}\text { C50 } \\
\text { concrete }\end{array}$ & 2500 & 34.5 & 0.167 & - \\
\hline $\begin{array}{l}\text { Side } \\
\text { walls } \\
\text { and } \\
\text { basebo } \\
\text { ard }\end{array}$ & $\begin{array}{c}\text { Prestressed } \\
\text { steel strand }\end{array}$ & 7850 & 180 & 0.3 & $\begin{array}{c}1.2 \times \\
10^{-5}\end{array}$ \\
\hline
\end{tabular}

\section{Calculation unit and failure criterion}

Use SOLID65 element to simulate the concrete unit, the unit is designed for concrete and rock compressive capacity greater than the tensile capacity of non-uniform material development unit. LINK8 element for prestressed steel strand, the unit of which is composed of 2 nodes, can simulate under axial force, not under bending moment, etc., and have plastic, creep, stress players, large strain and unit anyway, and other functions.

The constitutive relation of concrete material adopts the multiple linear and isotropic and strengthen model MISO, and use five parameters simulation William - Warner failure 
criteria are adopted to simulate failure criterion of concrete material.

TABLE 2 SINK BODY UNIT INFORMATION

\begin{tabular}{|l|c|c|}
\hline \multicolumn{1}{|c|}{ Unit type } & Unit number & Analog parts \\
\hline SOLID65 & 174616 & concrete \\
\hline LINK8 & 11020 & prestressed steel strand \\
\hline
\end{tabular}

\section{Constraint conditions and prestressed load}

30 meters span range can be seen as a simply supported beam aqueduct structure, namely one end is fixed hinge bearing, and the other end hinged support for activities, simulation of the load of the prestressed steel wire by the method of temperature drop. The original design of steel strand tension control stress of $1302 \mathrm{~N} / \mathrm{mm}$, the prestress loss value is calculated as $192.2 \mathrm{~N} / \mathrm{mm} 2$, therefore, this paper takes effective prestress of $1110 \mathrm{~N} / \mathrm{mm} 2$. According to the stress and the corresponding temperature change formula $\Delta \mathrm{T} \nexists \overline{\mathrm{A}} \alpha[7]$, we can calculate the effective prestress value converted to the equivalent temperature.

\section{ThE SCHEME RESEARCH ON CAOHE AqUEDUCT WITH THREE-WAY PRESTRESSED STEEL STRAND TENSION}

The Caohe Aqueduct has the characteristics of large streamflow, heavy load and complicated structure [8]. In the analysis of aqueduct structure design, after the completion of operation period, people often only consider under different working conditions, whether the whole aqueduct can meet the design requirements or not, ignoring how to safely and effectively carry out large thin-wall aqueduct as so much steel strand prestressing construction and the problems may encounter. People pay less attention to the problem that the tensile load classification and tensioning sequence changes may significantly affect the aqueduct structure system.

The purpose of this paper is to find a feasible plan for the optimization of the Three-way prestressed steel strand by the premise of ensuring the structure safety and the construction convenience, for the similar large three-way prestressed aqueduct and the structure of hydraulic construction to provide theoretical and technical support.

\section{A. The basis and thinking of the tension of prestressed steel strand}

There are more than 1000 prestressed steel strands in the aqueduct, and it's too multifarious for one-way prestressed optimized [9-10]. In order to simplify the process of the application of the prestress, the three-way prestressed steel strand should be divided into groups first. In the actual construction process of the aqueduct, it is impossible to satisfy one time stretch-draw according to the technical requirements, we need to grade tensioning, and in the process of tensioning to remove the scaffold in order to release self-respect. In this paper, the prestressed steel strand is divided into 10 stages and the release of the weight is gradually carried out, the minimum sink body maximum principal stress as the optimization goal, calculate and analyze the time to release the weight, and determined the three-way prestressed steel strand grading loading plan.

\section{B. The prestressed steel strand influence on the stress of the sink body structure}

(1)The calculation of sink body stress under only the effect of longitudinal prestressed reinforcement

Under the condition of empty slot, assuming that only longitudinal tensioning prestressed steel strand in the tank body, calculation and analysis the longitudinal prestressed steel strand influence on sink body structure, the influence of relevant results are shown in table 3.

TABLE 3 LONGITUdinal PRESTREsS For The IMPORTANT PARTS OF THE STRESS COMPONENT AND VERTICAL DISPLACEMENT RESULTS

\begin{tabular}{|c|c|c|c|c|}
\hline mid-span & $\sigma_{\mathrm{x}}(\mathbf{M P a})$ & $\sigma_{y}$ (MPa) & $\sigma_{\mathrm{z}}(\mathbf{M P a})$ & $\mu_{y(\mathbf{m m})}$ \\
\hline Side wall top & 0.007 & -0.004 & 0.594 & 1.682 \\
\hline $\begin{array}{l}\text { Edge bottom } \\
\text { beam }\end{array}$ & -0.065 & 0.007 & -3.909 & 1.645 \\
\hline $\begin{array}{l}\text { Side wall and } \\
\text { floor board }\end{array}$ & -0.341 & -0.132 & -2.687 & 1.707 \\
\hline $\begin{array}{l}\text { Middle wall } \\
\text { top }\end{array}$ & 0.062 & 0.002 & 1.065 & 1.990 \\
\hline $\begin{array}{l}\text { Middle } \\
\text { bottom beam }\end{array}$ & -0.085 & 0.012 & -4.284 & 1.954 \\
\hline $\begin{array}{lr}\begin{array}{l}\text { middle } \\
\text { and }\end{array} & \text { wall } \\
\text { board } & \\
\end{array}$ & -0.014 & -0.047 & -2.711 & 2.009 \\
\hline $\begin{array}{l}\text { Upper bottom } \\
\text { plate }\end{array}$ & 0.105 & 0.000 & -2.514 & 2.052 \\
\hline $\begin{array}{l}\text { Lower bottom } \\
\text { plate; }\end{array}$ & -0.261 & -0.002 & -3.368 & 2.045 \\
\hline bottom floor & -0.059 & -0.023 & -0.010 & 2.025 \\
\hline Tie rod & 0.404 & 0.000 & 0.000 & 1.943 \\
\hline Side rib & 0.008 & 0.367 & -0.014 & 1.684 \\
\hline
\end{tabular}

(2)The calculation of sink body stress under the effect of transverse prestressing reinforcement

Under the condition of empty slot, assuming that only transverse tensioning prestressed steel strand in the tank body, calculate and analysis the horizontal prestressed steel strand influence on sink body structure, the results are shown in table 4.

(3)The calculation of sink body stress under the effect of vertical prestressed reinforcement

Under the condition of empty slot, assuming that only vertical tensioning prestressed steel strand in the tank body, calculate and analysis the vertical prestressed steel strand influence on sink body structure, the results are shown in table 5. 
TABLE 4 TRANSVERSE PRESTRESS FOR THE IMPORTANT PARTS OF THE STRESS COMPONENT AND VERTICAL DISPLACEMENT RESULTS

\begin{tabular}{|c|c|c|c|c|}
\hline mid-span & $\sigma_{\mathrm{x}}$ (MPa) & $\sigma_{y}$ (MPa) & $\sigma_{\mathrm{z}}(\mathbf{M P a})$ & $\mu_{y}(\mathbf{m m})$ \\
\hline $\begin{array}{l}\text { Side wall } \\
\text { top }\end{array}$ & 0.020 & 0.002 & -0.194 & -0.158 \\
\hline $\begin{array}{l}\text { Edge } \\
\text { bottom } \\
\text { beam }\end{array}$ & 0.066 & -0.001 & 0.118 & -0.177 \\
\hline $\begin{array}{ll}\text { Side } & \text { wall } \\
\text { and } & \text { floor } \\
\text { board } & \\
\end{array}$ & -2.158 & -0.424 & -0.418 & -0.071 \\
\hline $\begin{array}{l}\text { Middle wall } \\
\text { top }\end{array}$ & -0.005 & -0.001 & 0.165 & 0.037 \\
\hline $\begin{array}{l}\text { Middle } \\
\text { bottom } \\
\text { beam }\end{array}$ & 0.081 & -0.003 & 0.125 & 0.031 \\
\hline $\begin{array}{l}\text { middle wall } \\
\text { and floor } \\
\text { board } \\
\end{array}$ & -3.083 & -0.625 & -0.474 & 0.052 \\
\hline $\begin{array}{l}\text { Upper } \\
\text { bottom plate }\end{array}$ & -0.910 & 0.000 & -0.048 & 0.273 \\
\hline $\begin{array}{l}\text { Lower } \\
\text { bottom } \\
\text { plate; }\end{array}$ & -2.896 & -0.002 & -0.033 & 0.269 \\
\hline bottom floor & -4.794 & -0.312 & -0.084 & 0.277 \\
\hline Tie rod & 0.146 & 0.000 & 0.000 & 0.138 \\
\hline Side rib & 0.000 & 0.156 & -0.001 & -0.253 \\
\hline
\end{tabular}

TABle 5 VERTICAL PRESTRESS FOR The IMPORTANT PARTS OF THE STRESS COMPONENT AND VERTICAL DISPLACEMENT RESULTS

\begin{tabular}{|c|c|c|c|c|}
\hline mid-span & $\sigma_{\mathrm{x}}$ (MPa) & $\sigma_{y}(\mathbf{M P a})$ & $\sigma_{z}(\mathbf{M P a})$ & $\mu_{y(\mathbf{m m})}$ \\
\hline $\begin{array}{l}\text { Side wall } \\
\text { top }\end{array}$ & 0.673 & -0.065 & 1.426 & -0.253 \\
\hline $\begin{array}{l}\text { Edge } \\
\text { bottom } \\
\text { beam }\end{array}$ & -0.078 & 0.004 & 0.673 & -0.005 \\
\hline $\begin{array}{ll}\text { Side } & \text { wall } \\
\text { and } & \text { floor } \\
\text { board } & \\
\end{array}$ & -0.052 & -0.152 & -0.017 & -0.025 \\
\hline $\begin{array}{l}\text { Middle wall } \\
\text { top }\end{array}$ & 0.020 & 0.001 & -0.008 & -0.022 \\
\hline $\begin{array}{l}\text { Middle } \\
\text { bottom } \\
\text { beam }\end{array}$ & -0.001 & 0.000 & 0.049 & -0.022 \\
\hline $\begin{array}{l}\text { middle wall } \\
\text { and floor } \\
\text { board }\end{array}$ & 0.015 & 0.003 & 0.034 & -0.022 \\
\hline $\begin{array}{l}\text { Upper } \\
\text { bottom plate }\end{array}$ & 0.015 & 0.000 & 0.030 & -0.023 \\
\hline $\begin{array}{l}\text { Lower } \\
\text { bottom } \\
\text { plate; }\end{array}$ & 0.021 & 0.000 & 0.041 & -0.023 \\
\hline bottom floor & 0.019 & 0.000 & 0.000 & -0.022 \\
\hline Tie rod & 0.056 & 0.000 & 0.000 & -0.016 \\
\hline Side rib & 0.001 & -1.854 & -0.002 & -0.175 \\
\hline
\end{tabular}

\section{(4) Results analysis}

By considering separately longitudinal prestressed steel strand, transverse prestressed steel strand and vertical prestressed steel strand on sink body structure deformation and stress distribution, a conclusion can be reached that the longitudinal prestressed steel strand give the bottom beam floor about -4.83MPa -2.514MPa longitudinal compressive stress, as well as it produce about $0.118 \mathrm{MPa} 1.103 \mathrm{MPa}$ longitudinal tensile stress near to the top of the sidewall in across; the transverse prestressed steel strand give the bottom and bottom rib about -4.794MPa -2.158MPa transverse compressive stress, as well as it produce about $0.594 \mathrm{MPa} \sim 1.065 \mathrm{MPa}$ longitudinal tensile stress at the end of beam; the vertical prestressed steel strand mainly give the side ribs maximum vertical compressive stress is $-1.854 \mathrm{MPa}$, and longitudinal tensile stress of $0.673 \mathrm{MPa} \sim 1.426 \mathrm{MPa}$ in the top and bottom of the side wall.

It can be seen that the longitudinal prestressing strand is a large amount of longitudinal tensile stress produced by the gravity, and the transverse tensile stress caused by the gravity force, and the vertical prestressed strand is not obvious. Therefore, it should be the first one to pull the longitudinal prestressed steel strand, and then pull the transverse prestressed steel strand, to a certain extent, the release of self-weight, and the final tension of vertical prestressed steel.

\section{Study on the classification of the three- way prestressed steel strand}

From the above analysis, it can be known that the cross section of the side wall and the floor of the transfer, the middle wall and the bottom of the slab, and the role of the side ribs in the prestressing tendons, stress is not large, so it will not be considered in the following analysis.

(1)The study of the longitudinal prestressed steel strand tensioning grading

All longitudinal reinforcement are divided into 10 levels (according to the steel strand tension load / 10) and release the weight at the same time, it can be seen in fig. (4): the tensile stress in the side sill and sill transform into compressive stress in the process of $30 \% \sim 40 \%$, and tensile stress on the floor and floor transform into compressive stress in the process of $10 \%$ $20 \%$.

(2)The study of the transverse prestressed steel strand tensioning grading

All transverse prestressing tendons are divided into 10 stages with the release of self-weight at the same time, it can be seen from fig. (5) that on the bottom plate and the bottom plate in the $20 \% \sim 30 \%$ process, the tensile stress transform into compressive stress.

(3)The study of the vertical prestressed steel strand tensioning grading

All vertical prestressing tendons are divided into 10 stages with the release of self-weight at the same time, it can be seen in Fig. (6): the sink body structure of vertical prestressed caused by gravity stress has little effect, so it could be considered the last applied vertical prestressed reinforcement. 
From the above calculation, a conclusion can be drawn that the longitudinal and transverse prestressing tendons play a major role in the release of self-weight, after the sink body concrete pouring is completed and maintenance to $75 \%$ of design strength of concrete, In case of no installation of the groove top rod, Three levels of $40 \%, 70 \%, 100 \%$, the tensile steel strand, and after $40 \%$ of prestressed tendons are applied in demolition lower support scaffolding, to release of weight. The reinforcement tensioning sequence is that: first longitudinal, than transverse and vertical in the end. The placement or installation of the top rod of the groove is carried out after the prestressing force is applied.

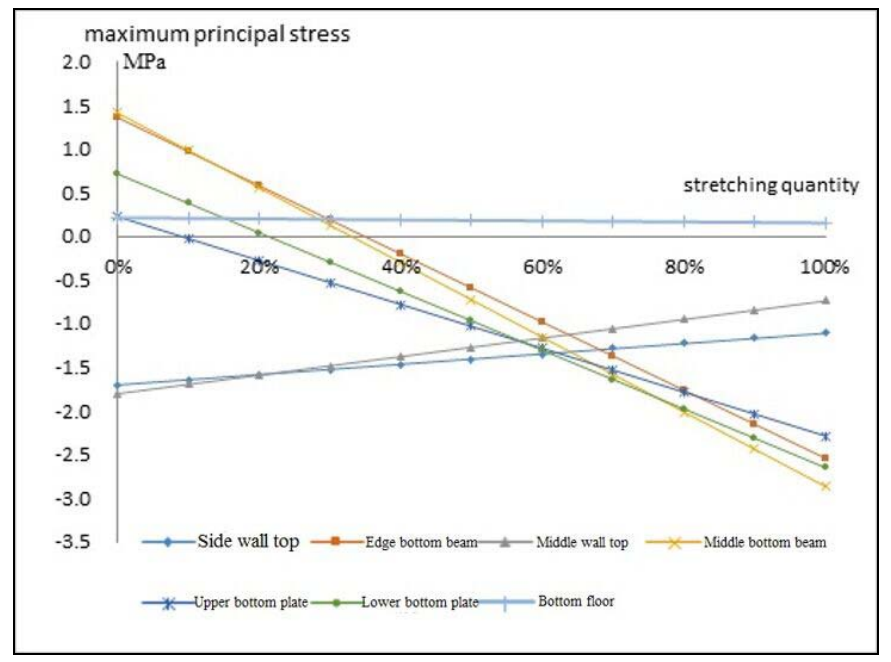

Fig.4 Relationship between the maximum principal stresses of the longitudinal pre stressed tendons and the release of the gravity of the load

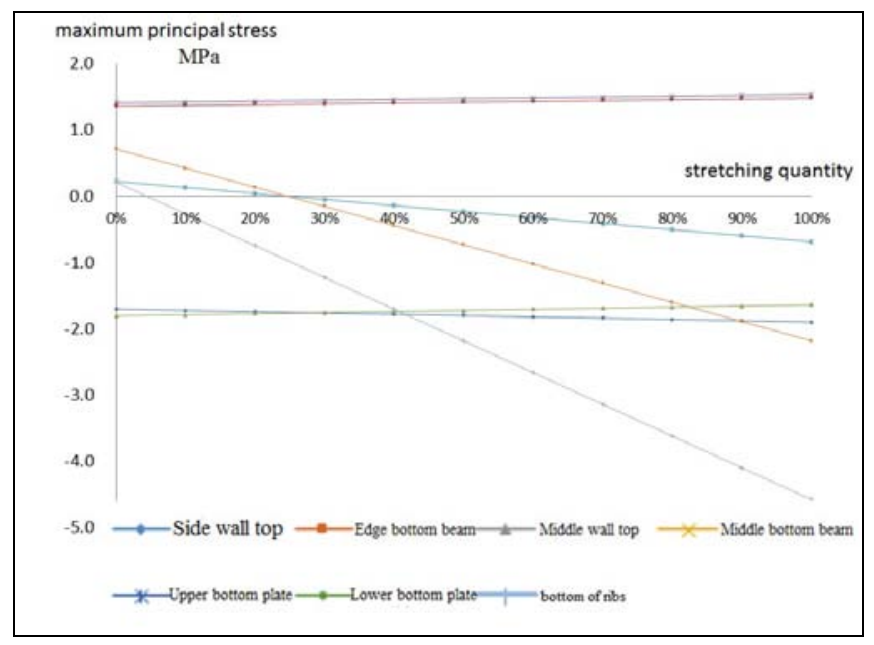

Fig.5 Relationship between the maximum principal stresses of the transverse pre stressed tendons and the release of the gravity of the load

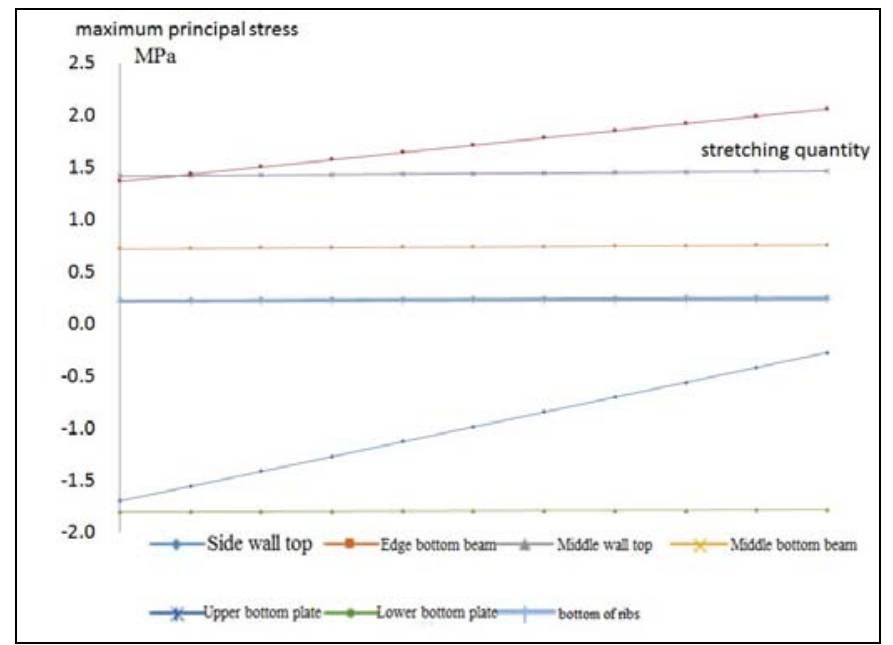

Fig.6 Relationship between the maximum principal stresses of the vertical pre stressed tendons and the release of the gravity of the load

\section{MAIN CONCLUSIONS}

Taking the Caohe Aqueduct on the Beijing-Shijiazhuang section of route project as the research object, the author adopts three dimensional finite element analysis method to analyze the prestressed steel strand prestressed steel strand, horizontal, vertical prestressed steel strand on sink body structure deformation and stress distribution. The following conclusions can be got from the above analysis:

(1) The longitudinal prestressing strand is mainly shared by a large number of longitudinal tensile stresses produced by the gravity at the tank body structure. The transverse prestressing strand is shared by the transverse tension stress generated by the gravity at the bottom and the bottom ribs. There is no obvious effect of vertical prestressed steel strand on the stress relief of the groove body. Transverse prestressing stress steel strand is not significant in reducing the stress of the groove body than longitudinal prestressing strand.

(2) After the sink body concrete pouring is completed and maintenance to $75 \%$ of design strength of concrete, in case of no installation of the groove top rod, three levels of $40 \%, 70 \%$, $100 \%$, the tensile steel strand, and after $40 \%$ of prestressed tendons are applied in demolition lower support scaffolding, for the purpose to release weight.

(3) The three-way prestressed steel strand tensioning sequence is that: first longitudinal, than transverse and vertical for the final tensioning construction.

\section{References}

[1] Guangdong province water conservancy electric power survey design institute, Dongjiang-shenzhen water supply reconstruction project of aqueduct structure design optimization research report, In August 2000.

[2] Zhao Wenhua. Aqueduct [M]. Hydraulic power press, 1983.

[3] Zhu Huizhu, Chen Deliang, and Guan Fengnian, Aqueduct [M] .Beijing: China Water\&Power Press.

[4] Li Guoping. Design principle of prestressed concrete structure [M]. Beijing: People's Communications Press, 2000. 
[5] Liu Yongyi, Feng Dabin. Development and Prospect of China's pre stress technology [J]. Construction technology, 1999, 28 (12): 2-4.

[6] Lu Shusheng. Modern prestressed concrete theory and application [M]. Beijing: Chinese Railway Press, 2007:3-6.

[7] Liu Yongyi. Looking into the eighth annual meeting of the China Civil Engineering Society of China [A]. [C], 1998

[8] Zheng Chongyang, Peng Hui, Ren Deji. Three dimensional finite element analysis of Ji He aqueduct in South North diversion project [J]. Yangtze River Scientific Research Institute in the college newspaper, the 2013, 05:86-91.
[9] Wang Changde, Zhu Yiwen, He Yingming In middle route of South to North Water Diversion Project new car beam type aqueduct structure design and research [J]. Journal of Hydraulic Engineering, 1998 (3): 5255.

[10] Liu Shao-lin, Peng Hui, Zheng Chong-yang, Yan Qin-long,etc. Static Analysis of Bonding Steel Technique for Diversion Tunnel on Hualiangting Reservoir [J]. Applied Mechanics and Materials, 2012, Vol.212: 810-814. 